\title{
Characteristics of cardiorespiratory output determining factors among 11-19-year-old boys at rest and during maximal load: Its impact on systolic hypertension
}

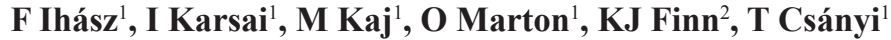 \\ ${ }^{1}$ Hungarian School Sport Federation, Budapest, Hungary \\ ${ }^{2}$ University of Northern Iowa, Cedar Falls, IA, USA
}

Received: April 7, 2014

Accepted after revision: June 22, 2015

\begin{abstract}
As consequence of the expansion of sedentary lifestyle among schoolchildren the prevalence of particular symptoms related to decreased cardiorespiratory fitness increases. The purpose of this study was twofolds, on one hand to compare boys in three developmental groups: second childhood (G1), puberty (G2), young adult (G3) and on the other hand to compare groups classified on resting systolic blood pressure (RSBP) to differentiate cardiorespiratory output determining factors both at rest and at maximal load. Randomly selected apparently healthy boys were assessed, all subjects $(n=282)$ performed an incremental treadmill test until fatigue. Heart rate (HR), systolic and diastolic blood pressure (SBP and DBP), and oxygen consumption were measured. Resting HR was higher and resting SBP and DBP were lower in the G1 as compared to G2 and G3 $(p<0.05)$ but not differed at maximal loads. However indicators of cardiovascular load differed between groups. The oxygen pulse and $\mathrm{Q}$ were the lowest in the G1 and increased significantly between groups $(p<0.05)$. In conclusion based on our data we can suggest that there is an observable development of hypertension associated with maturation and cardiac output determining factors.

Keywords: environmental factors, maximal cardiorespiratory load, resting blood pressure, incremental workload, systolic hypertension
\end{abstract}

\section{Introduction}

Essential hypertension begins in early childhood. Children tracking at the high percentiles based upon (body size, age, sex, actual level of maturation) can be identified and are candidates for early intervention. The key to early prevention of essential hypertension is to influence children and adolescents to adopt lifestyles that promote good health and prevent development of cardiovascular risk factors. The hypothesis that elevated blood pressure in adults is rooted in childhood is gaining increasing acceptance and attention $(21,24)$. If the determinants of blood pressure levels are operative years before elevated blood pressure becomes apparent $(7,31,33)$, a strategy of intervention in childhood would be preferable to present approaches directed largely toward early diagnosis and treatment of clinically established hypertension in adults $(29,34,35)$. Current views regarding elevated blood pressure include the concept that an underlying hereditary susceptibility is acted upon by several personal and environmental factors over a period of many years to mediate a combination of pathophysiologic changes resulting ultimately in the well-known consequences of persistent blood pressure elevation (hypertension). Among personal

Corresponding author: Ferenc Ihász, $\mathrm{PhD}$

Apáczai Csere János Faculty, West Hungarian University

Liszt Ferenc út 42, H-9022 Győr, Hungary

Phone: +36-30-532-2022; E-mail: ihasz@atif.hu 
characteristics suspected to play an important role are psychosocial traits $(6,12,15,17,19$, $23,32)$, dietary habits $(2,3,20)$, physical fitness $(4,5,8,26,22)$, and obesity $(13,18)$, although data supporting the roles of these factors are subject to differing interpretations.

Isolated systolic hypertension is a condition in which resting systolic blood pressure is high but diastolic blood pressure is within expected levels. This condition is shown to be more common than diastolic hypertension and its prevalence has been linked to cardiovascular morbidity in adults (30). In children and adolescents, this condition has also been suggested as possible precursor to adult hypertension. Thus recognizing the factors associated with systolic hypertension would be beneficial to both prevention and treatment options for cardiovascular disease.

Age and gender can influence the blood pressure at rest and exercise due to natural growth, development, and maturation. Thus, in recognizing factors associated with hypertension in youth, separation of gender and age should be considered as well as the potential influence of maturation in the growth and development of the cardiovascular system. Since boys differ in maturation from girls in body composition, each gender must be interpreted in separate analyses. The effect maturation has on development of systolic hypertension suggests also that age associated with periods of maturation should be compared to see if changes in accelerated growth and development of secondary sexual characteristics might have an influence on the presence of hypertension in youth. Finally, if risk of hypertension is linked to body fat, a comparison of body composition should be made in groups that are normal, at risk of, and with hypertension. These studies would provide potential hypothesis as to the cause of hypertension.

Exercise provides a stress to the blood vessels due to higher blood flow with increased cardiac output. The cardiovascular health of the child can be evaluated during a maximal exertion which challenges the cardiovascular mechanism by which to suggestive potential risk for development of heart disease. Evaluation of the exercise response of blood pressure during maximal exertion can add valuable information as to the need to intervene in children with hypertension.

The aim of this study was therefore, to examine the influences of the group differences for age and classification of health from resting blood pressure to identify possible factors associate with isolated systolic hypertension in children and adolescents.

The following questions were raised:

1) Are there any differences between the averages of age-group selected samples in anthropometric, blood-pressure and characteristics of the cardio-respiratory system during rest and at maximum load?

2) Are there any differences between the averages of the characteristics of body composition and cardio-respiratory samples that were selected prehypertensive and hypertensive based on resting blood pressure?

3) Is the systolic and diastolic pressure - that has been measured at maximum load different between groups according to age and resting blood pressure?

\section{Materials and Methods}

\section{Participants and settings}

Two hundred and seventy-five $(n=282)$ apparently healthy boys ranging from 11 to 19 years (mean age $=15.16 \pm 2.3$ ) were recruited from sixteen public secondary and four "eight years" high schools. According to Scammon's classification (31) we created three age groups 
"second childhood" (G1), puberty (G2) and young adult (G3). G1 group includes boys who are between 8.0-12.5 years old, while G2 and G3 includes boys 12.6-16.5 years and 16.621.0 years old, respectively. Resting systolic blood pressure RSBP groups: normal RSBP (NRSBP), prehypertensive RSBP (PRSBP) and high BP RSBP (HRSBP) were classified based on height and age percentile charts $(17,26)$. Subjects above the $95^{\text {th }}$ percentile were classified as hypertensive while the subjects between $90^{\text {th }}-95^{\text {th }}$ percentiles were identified as prehypertensive.

Data collection was taken in five different towns (Budapest, Győr, Pécs, Nyíregyháza, Szeged), in five different regional laboratories of Hungary. The laboratory tests were performed by five different working groups using similar methods and instruments with the same testing protocol. In each working group worked physiologist and medical assistant were present to manage unexpected incidents.

\section{Body dimensions and body content}

Anthropometric measurements of body stature were recorded to the nearest $0.1 \mathrm{~cm}$ (SieberHagner, Switzerland) based on the International Biological Program (37). For this study, the "InBody720" (Biospace Co. Inc., Seoul, South Korea) Bioelectrical Impedance Analyzer (BIA) was used to assess body mass and composition. This foot-to-foot, hand-to-hand and hand-to-foot contact device uses two stainless-steel foot pad electrodes mounted on a platform scale and two stainless-steel handles to allow for "Tetra polar" 8-point tactile electrode system. A multi-frequency (six) current is applied to determine 30 impedance measures ( 5 paths $\times 6$ frequencies). These measures are integrated into the system to provide output measures of total body water, intracellular water, extracellular water, and segmental lean analysis. Body fat percentage $(\mathrm{InBF} \%)$ is calculated using a summation of segmental lean analysis to determine total lean body mass, fat mass, and ultimately the proportion of fat to total weight mass fraction.

\section{Resting blood pressure}

Resting blood pressure was measured using the auscultator method by a trained medical assistant. Systolic and diastolic pressures were recorded at the appearance and disappearance of "Korotkoff" sounds, respectively. Resting blood pressure was assessed in the left upper arm after the subject had been sitting quietly for a minimum of four minutes, repeated three times in row, with two minutes break between each measurement. The average of the three measurements was used to determine resting blood pressure. Blood pressure cuffs were used that covered at least two thirds of the upper arm with the bladder encompassing most of the circumference of the arm without overlapping. This resting blood pressure value was obtained as a preliminary measure when the subject came to the laboratory for exercise testing. The resting blood pressure was taken at least two hours prior to any physical testing in the morning when the subject was fasted (no breakfast) prior to body composition measures.

\section{Physiological exercise testing}

Subjects were asked to walk (and run) on "Marquette" 2000 treadmill (Pittsburgh, PA, USA) using the personalized maximal exercise testing protocols, based on the expected fitness level of them. The following parameters were measured: resting (pre-exercise) heart rate $(\mathrm{RHR})$, (beat $\cdot \mathrm{min}^{-1}$ ), the maximal heart rate $(\mathrm{MaxHR})$, (beat $\cdot \mathrm{min}^{-1}$ ) using the "Cardiosoft", Cardiological System ECG (Milwaukee, USA); aerobic capacity (VO2max), and ventilation VE (BTPS $1 \cdot \mathrm{min}^{-1}$ ) using the Sensor medics "Vmax 29C" (Yorba Linda, CA, USA) device. Metabolic analysis software calculated the relative aerobic capacity 
$(\mathrm{RVO} 2 \mathrm{max}) ;\left(\mathrm{ml} \times \mathrm{kg}^{-1} \times \mathrm{min}^{-1}\right)$ and oxygen pulse $\left(\mathrm{O} 2 \mathrm{P}=\mathrm{VO} 2 \times \mathrm{HR}^{-1}\right) ;\left(\mathrm{ml} \times\right.$ beat $\left.{ }^{-1}\right)$, estimated cardiac output $\mathrm{Q}=$ StrokeVolume $\times \mathrm{RHR})\left(1 \times \mathrm{min}^{-1}\right)$ and relative ventilation $(\mathrm{RVE}=$ $\left.\mathrm{VE} \times \mathrm{BMass}^{-1}\right)$; $\left(1 \times \mathrm{kg}^{-1} \times \mathrm{min}^{-1}\right)$. Maximum blood pressure was measured during the final stages of the maximal exercise test with the "Tango" type automatic blood pressure monitor (SunTech ${ }^{\circledR}$ Medical Instruments Inc., Raleigh, NC, USA).

\section{Data reduction and statistical analyses}

Pulse pressure was calculated using the difference between systolic and diastolic pressures (PP = SBP.-DBP.); which provided for calculation of mean arterial blood pressure (MAP = $\mathrm{DBP}+\mathrm{PP} / 3)$. The total peripheral systemic resistance was calculated using mean arterial pressure and cardiac output $[\mathrm{TPSR}=(\mathrm{MAP}-4) / \mathrm{Q}]$.

Database analysis was performed using the STATISTICA 12.0 software (Stat. Soft. Inc., USA). Data are presented as mean and standard deviation (SD). Anthropometric, body content characterized data and resting and load level physiological measured and calculated data were compared with ANOVA with a Post Hoc comparison using a Tukey HSD test. A $p$ value of $<0.05$ was considered as statistically significant.

\section{Results}

Table I shows the anthropometric and body composition characteristics as well as the averages of cardiorespiratory performance of the examined children during rest grouped in age categories. The averages of the age groups height and body mass is continuously increasing, according the ANOVA test there is a main effect present $\left(F_{(2,272}=161.13, p<0.001\right.$ and $F_{(2,272)}$ $=71.70, p<0.001$, respectively) according the post hoc analysis, the differences between the G1-G2 and G1-G3 $(p<0.05)$ and G1-G2 $(p<0.05)$, respectively significant. The averages of InBF\% decreases as age progresses. The average R-HR of the age groups decreased significantly $\left(F_{(2,274)}=29.91, p<0.001\right)$, with significant $(p<0.05)$ differences between G1G2 as well as G1-G3. Averages of HR measured at maximum load (MaxHR) showed no difference between age groups. Regarding the average RSBP we explored a significant main effect $\left(F_{(2,274)}=11.98, p<0.001\right)$. The differences between the age groups G1-G2 as well as the G1-G3 groups are significant $(p<0.05)$. Significant main effect were found between age group selected averages of PP and $\operatorname{MAP}\left(F_{(2,274)}=4.82, p<0.001\right.$ and $F_{(2,274)}=11.89, p<$ $0.001)$ post hoc test showed significant differences between G1-G2 and G1-G3 $(p<0.05)$.

Table II shows the maximal exercise response for each age category. Systolic and diastolic values measured at maximum load (MSBP and MDBP) do not show any significant difference between age groups. We have found significant main effect for the means of TPSR $\left(F_{(2,274)}=20.85, p<0.001\right), \mathrm{O} 2 \mathrm{P}\left(F_{(2,274)}=33.85, p<0.001\right), \mathrm{Q}\left(F_{(2,274)}=33.67, p<0.001\right)$ and $\operatorname{VE}\left(F_{(2,274)}=77.04, p<0.001\right)$, according the post hoc analysis we have found significant difference $(p<0.05)$ between all three age groups except for the RVO2max where only between the G1-G3 shoved significant difference $(p<0.05)$.

Tables III and IV contains the anthropometrical, body composition and cardio-respiratory system characteristics of samples that have been selected based on RSBP. Regarding the RSBP values of the examined 11-19-year-old boys, 29.8\%; $(n=82)$ were hypertensive, $8.7 \%$; $(n=24)$ were prehypertensive, and by $61.5 \%(n=169)$ were normal SBP measured. 
Table I. Age groups selected antropometric body composition characteristics and cardiovascular responses at resting (Mean and $\mathrm{SD})$

\begin{tabular}{|c|c|c|c|c|c|c|}
\hline \multirow[t]{2}{*}{ Age groups } & \multicolumn{2}{|c|}{ G1 (68) } & \multicolumn{2}{|c|}{ G2 (101) } & \multicolumn{2}{|c|}{ G3 (113) } \\
\hline & Mean & SD & Mean & SD & Mean & SD \\
\hline $\begin{array}{l}\text { Age } \\
\text { (years) }\end{array}$ & 12.04 & 0.58 & 14.65 & 0.96 & 17.50 & 0.82 \\
\hline $\begin{array}{l}\text { Height }{ }^{a, b, c} \\
(\mathrm{~cm})\end{array}$ & 153.82 & 8.49 & 169.54 & 9.80 & 176.83 & 6.78 \\
\hline $\begin{array}{l}\text { Body Mass }{ }^{\text {a, b, c }} \\
(\mathrm{kg})\end{array}$ & 45.90 & 10.80 & 60.94 & 14.87 & 69.66 & 12.22 \\
\hline $\mathrm{InBF} \%$ a, c & 25.98 & 10.20 & 17.61 & 9.70 & 15.85 & 6.52 \\
\hline $\begin{array}{l}\text { RHR }{ }^{\mathrm{a}, \mathrm{c}} \\
\left(\text { beat } \times \mathrm{min}^{-1}\right)\end{array}$ & 83.30 & 13.47 & 76.51 & 12.35 & 72.97 & 12.15 \\
\hline $\begin{array}{l}\mathrm{RSBP}^{\mathrm{a}, \mathrm{c}} \\
(\mathrm{Hgmm})\end{array}$ & 116.71 & 16.91 & 127.26 & 15.61 & 128.14 & 15.75 \\
\hline $\begin{array}{l}\text { RDBP a,c } \\
(\mathrm{Hgmm})\end{array}$ & 68.61 & 11.13 & 72.47 & 10.00 & 73.88 & 9.12 \\
\hline $\begin{array}{l}\mathrm{PP}^{\mathrm{a}, \mathrm{c}} \\
(\mathrm{Hgmm})\end{array}$ & 48.25 & 14.72 & 54.84 & 13.24 & 54.46 & 15.46 \\
\hline $\begin{array}{l}\text { MAP a,c } \\
(\mathrm{Hgmm})\end{array}$ & 84.50 & 11.32 & 90.72 & 10.51 & 92.03 & 9.01 \\
\hline $\begin{array}{l}\text { TPSR } \\
\text { (Hgmm) }\end{array}$ & 3.86 & 0.92 & 3.40 & 1.00 & 2.88 & 0.62 \\
\hline
\end{tabular}

$p<0.05$

a - G1 vs. G2, ${ }^{b}-\mathrm{G} 2$ vs. G3, ${ }^{\mathrm{c}}-\mathrm{G} 1$ vs. G3

Abbreviations: $\mathrm{InBF} \%$ = relative body fat content, $\mathrm{RHR}=$ resting heart rate, $\mathrm{RSBP}=$ resting systolic blood pressure, $\mathrm{RDBP}=$ resting diastolic blood pressure, $\mathrm{PP}=$ pulse pressure, $\mathrm{MAP}=$ average arterial blood pressure, TPSR $=$ total peripheral systemic resistance.

Table II. Maximal exercise response by age groups

\begin{tabular}{|l|c|c|c|c|c|c|}
\hline \multirow{2}{*}{ Age groups } & \multicolumn{2}{c|}{ G1 (68) } & \multicolumn{2}{c|}{ G2 (101) } & \multicolumn{2}{c|}{ G3 (113) } \\
\cline { 2 - 7 } & Mean & SD & Mean & SD & Mean & SD \\
\hline $\begin{array}{l}\text { MaxHR } \\
\left(\text { beat } \times \min ^{-1}\right)\end{array}$ & 194.47 & 9.32 & 195.98 & 8.74 & 193.14 & 11.00 \\
\hline $\begin{array}{l}\text { MaxSBP } \\
(\mathrm{Hgmm})\end{array}$ & 165.87 & 22.75 & 167.07 & 22.72 & 167.75 & 22.55 \\
\hline $\begin{array}{l}\text { MaxDBP } \\
(\mathrm{Hgmm})\end{array}$ & 54.69 & 25.22 & 57.45 & 26.99 & 55.33 & 32.23 \\
\hline $\begin{array}{l}\text { RVO2max } \\
\left(\mathrm{ml} \times \mathrm{kg}^{-1} \times \min ^{-1}\right)\end{array}$ & 46.58 & 10.07 & 45.99 & 8.79 & 46.39 & 7.80 \\
\hline $\begin{array}{l}\text { Q } \\
\left(1 \times \mathrm{min}^{-1}\right)\end{array}$ & 21.38 & 6.81 & 27.51 & 8.11 & 32.01 & 7.05 \\
\hline $\begin{array}{l}\text { O2P } \\
\left(\mathrm{ml} \times \mathrm{beat}^{-1}\right)\end{array}$ & 10.97 & 3.49 & 14.08 & 4.28 & 16.67 & 3.95 \\
\hline
\end{tabular}


Table II. (cont.)

\begin{tabular}{|l|c|c|c|c|c|c|}
\hline \multirow{2}{*}{ Age groups } & \multicolumn{2}{|c|}{ G1 (68) } & \multicolumn{2}{c|}{ G2 (101) } & \multicolumn{2}{c|}{ G3 (113) } \\
\cline { 2 - 7 } & Mean & SD & Mean & SD & Mean & SD \\
\hline $\begin{array}{l}\text { VE }(\text { BPTS }) \\
\left(1 \times \mathrm{min}^{-1}\right)\end{array}$ & 68.20 & 14.32 & 92.26 & 23.24 & 110.59 & 22.36 \\
\hline $\begin{array}{l}\text { RVE } \\
\left(1 \times \mathrm{kg}^{-1} \times \mathrm{min}^{-1}\right)\end{array}$ & 1.49 & 0.35 & 1.56 & 0.30 & 1.61 & 0.34 \\
\hline
\end{tabular}

$p<0.05$

${ }^{\mathrm{a}}-\mathrm{G} 1$ vs. G2, ${ }^{\mathrm{b}}-\mathrm{G} 2$ vs. G3, ${ }^{\mathrm{c}}-\mathrm{G} 1$ vs. G3

Abbreviations: MaxHR = maximum heart rate, MaxSBP $=$ maximum systolic blood pressure,

MaxDBP = maximum diastolic blood pressure, TPSR $=$ total peripheral systemic resistance,

$\mathrm{RVO} 2 \mathrm{max}=$ maximum relative aerobe capacity, $\mathrm{Q}=$ cardiac output, $\mathrm{O} 2 \mathrm{P}=$ stroke volume,

$\mathrm{VE}(\mathrm{BPTS})=$ ventilation, $\mathrm{RVE}=$ relative ventilation .

Table III. Blood pressure groups antropometric body composition characteristics and cardiovascular responses at rest (Mean and SD)

\begin{tabular}{|c|c|c|c|c|c|c|}
\hline \multirow[t]{2}{*}{ RSBP groups } & \multicolumn{2}{|c|}{$\begin{array}{c}\text { NRSBP } \\
(61.5 \%)(n=169)\end{array}$} & \multicolumn{2}{|c|}{$\begin{array}{c}\text { PRSBP } \\
(8.7 \%)(n=24)\end{array}$} & \multicolumn{2}{|c|}{$\begin{array}{c}\text { HRSBP } \\
(29.8 \%)(n=82)\end{array}$} \\
\hline & Mean & SD & Mean & SD & Mean & SD \\
\hline $\begin{array}{l}\text { Age } \\
\text { (years) }\end{array}$ & 15.23 & 2.39 & 15.41 & 1.85 & 14.54 & 2.29 \\
\hline $\begin{array}{l}\text { Height }{ }^{a, c} \\
(\mathrm{~cm})\end{array}$ & 168.71 & 13.13 & 175.97 & 6.2 & 166.81 & 10.75 \\
\hline $\begin{array}{l}\text { Body Mass }^{a} \\
(\mathrm{~kg})\end{array}$ & 58.88 & 16.46 & 67.75 & 12.06 & 63.05 & 14.39 \\
\hline $\mathrm{InBF} \%$ & 20.13 & 10.65 & 18.17 & 8.96 & 18.42 & 8.24 \\
\hline $\begin{array}{l}\text { RHR } \\
\left(\text { beat } \times \min ^{-1} \text { ) }\right.\end{array}$ & 76.38 & 13.56 & 79.73 & 12.36 & 78.04 & 12.7 \\
\hline $\begin{array}{l}\mathrm{RSBP}^{\mathrm{a}, \mathrm{b}, \mathrm{c}} \\
(\mathrm{Hgmm})\end{array}$ & 115.31 & 10.56 & 131.17 & 3.55 & 143.65 & 11.62 \\
\hline $\begin{array}{l}\text { RDBP a, b, c } \\
\text { (Hgmm) }\end{array}$ & 69.6 & 8.9 & 74.67 & 7.15 & 76.04 & 9.86 \\
\hline $\begin{array}{l}\mathrm{PP}^{\mathrm{a}, \mathrm{b}, \mathrm{c}} \\
(\mathrm{Hgmm})\end{array}$ & 45.7 & 9.82 & 56.5 & 8.22 & 67.49 & 13.69 \\
\hline $\begin{array}{l}\text { MAP a, b, c } \\
(\mathrm{Hgmm})\end{array}$ & 84.83 & 8.22 & 93.5 & 4.82 & 99.18 & 9.33 \\
\hline $\begin{array}{l}\text { TPSR } \\
\text { (Hgmm) }\end{array}$ & 3.29 & 0.94 & 2.98 & 0.63 & 3.42 & 0.95 \\
\hline
\end{tabular}

$p<0.05$

${ }^{\mathrm{a}}-\mathrm{NRSBP}$ vs. PRSBP, ${ }^{\mathrm{b}}-\mathrm{PRSBP}$ vs. HRSBP, ${ }^{\mathrm{c}}-\mathrm{NRSBP}$ vs. HRSBP

Abbreviations: $\mathrm{InBF} \%$ = relative body fat content, $\mathrm{RHR}=$ resting heart rate, $\mathrm{RSBP}=$ resting systolic blood pressure, $\mathrm{RDBP}=$ resting diastolic blood pressure, $\mathrm{PP}=$ pulse pressure, $\mathrm{MAP}=$ average arterial blood pressure, TPSR $=$ total peripheral systemic resistance. 
Table $I V$. Exercise response by blood pressure groups

\begin{tabular}{|c|c|c|c|c|c|c|}
\hline \multirow[t]{2}{*}{ BP groups } & \multicolumn{2}{|c|}{$\begin{array}{c}\text { Normal } \\
(61.5 \%)(n=169)\end{array}$} & \multicolumn{2}{|c|}{$\begin{array}{c}\text { Prehypertensive }(8.7 \%) \\
\qquad(n=24)\end{array}$} & \multicolumn{2}{|c|}{$\begin{array}{c}\text { High BP } \\
(29.8 \%)(n=82)\end{array}$} \\
\hline & Mean & SD & Mean & SD & Mean & SD \\
\hline $\begin{array}{l}\text { MaxHR } \\
\left(\text { beat } \times \min ^{-1}\right)\end{array}$ & 193.82 & 10.97 & 193.72 & 7.66 & 196.04 & 7.99 \\
\hline $\begin{array}{l}\text { Max. sys. }{ }^{b, c} \\
\text { (Hgmm) }\end{array}$ & 159.22 & 18.63 & 166.75 & 24.04 & 181.08 & 21.69 \\
\hline $\begin{array}{l}\text { Max. dias. } \\
(\mathrm{Hgmm})\end{array}$ & 55.67 & 25.94 & 53.81 & 27.93 & 56.91 & 33.93 \\
\hline $\begin{array}{l}\text { RVO2max } \\
\left.\left(\mathrm{ml} \times \mathrm{kg}^{-1}\right) \times \min ^{-1}\right)\end{array}$ & 45.86 & 8.75 & 46.86 & 8.66 & 46.94 & 9.02 \\
\hline $\begin{array}{l}\mathrm{Q}^{\mathrm{a}} \\
\left(1 \times \min ^{-1}\right)\end{array}$ & 26.76 & 8.51 & 31.87 & 6.33 & 29.24 & 8.21 \\
\hline $\begin{array}{l}\mathrm{O} 2 \mathrm{P}^{\mathrm{a}} \\
\left(\mathrm{ml} \times \text { beat }^{-1}\right)\end{array}$ & 13.89 & 4.72 & 16.56 & 3.37 & 14.90 & 4.15 \\
\hline $\begin{array}{l}\mathrm{VE}(\mathrm{BPTS}) \\
\left(1 \times \min ^{-1}\right)\end{array}$ & 93.38 & 28.07 & 103.41 & 25.86 & 93.65 & 23.8 \\
\hline $\begin{array}{l}\text { RVE } \\
\left(1 \times \mathrm{kg}^{-1} \times \min ^{-1}\right)\end{array}$ & 1.58 & 0.33 & 1.6 & 0.28 & 1.48 & 0.32 \\
\hline
\end{tabular}

$p<0.05$

${ }^{a}-$ NRSBP vs. PRSBP, ${ }^{b}-$ PRSBP vs. HRSBP, ${ }^{c}-$ NRSBP vs. HRSBP

Abbreviations: MaxHR $=$ maximum heart rate, $\operatorname{MaxSBP}=$ maximum systolic blood pressure,

$\mathrm{MaxDBP}=$ maximum diastolic blood pressure, TPSR $=$ total peripheral systemic resistance,

$\mathrm{RVO} 2 \mathrm{max}=$ maximum relative aerobe capacity, $\mathrm{Q}=$ cardiac output, $\mathrm{O} 2 \mathrm{P}=$ stroke volume,

$\mathrm{VE}(\mathrm{BPTS})=$ ventilation, $\mathrm{RVE}=$ relative ventilation .

No significant main effect was found regarding the age between the RSBP groups. Significant main effect was found between the RSBP groups regarding the height $\left(F_{(2,274)}=\right.$ $12.24, p<0.001)$ and body mass $\left(F_{(2,274)}=21.79, p<0.001\right)$ as well as $\operatorname{RHR}\left(F_{(2,273)}=7.24 p\right.$ $<0.001)$. The NRSBP subjects are shorter, and lighter than the PRSBP group and the HRSBP group heavier than the NSBP group There was no difference between values measured at maximum load and relative body fat percentages. Averages of (RSBP) as well as MSBP $\left(F_{(2,274)}=207.8, p<0.001\right.$ and $\left.F_{(2,274)}=14.65, p<0.001\right)$ and RDBP of different RSBP groups are significantly different $\left(F_{(2,274)}=207.8, p<0.001\right)$. A similar relation can be seen in the case of $\operatorname{PP}\left(F_{(2,274)}=107.25, p<0.001\right)$ and $\operatorname{MAP}\left(F_{(2,27)}=82.25, p<0.001\right)$. In regards to averages of RVO2max, no significant differences have been found. Averages of O2P $\left(F_{(2,274)}=15.54, p\right.$ $<0.001)$ and $\mathrm{Q}\left(F_{(2,274)}=14,31, p<0.001\right)$ show significant differences among RSBP groups, according the post hoc analysis, significant difference exist between NRSBP and PRSBP groups $(p<0.05)$, however VE did not show significant difference between RSBP groups.

\section{Discussion}

In the case of adults, hypertension has long been perceived as a public health problem. The determinants of blood pressure during childhood may also be important predictors of adult blood pressure levels (11). Recent epidemiologic studies of pediatric populations have 
demonstrated equivocal results regarding the tendency of children whose initial blood pressures are in the higher percentiles to have higher blood pressures on follow-up 2 years later (16). Almost 30\% of the 11-19 year old boys had high blood pressure and we have measured (8.7\%) had elevated resting systolic pressure. Neuhauser and Thamm (29) in 2009, measured blood pressure in 14730 children aged 3-17 years (7203 girls and 7527 boys) participating in a nationally representative examination survey of children and adolescents living in Germany (The German Health Interview and Examination Survey for Children and Adolescents). For this study, the prevalence of higher-than-optimal blood pressure values by adult criteria ( $>$ or $=120 / 80 \mathrm{mmHg}$ ) increased with age and was $52.2 \%$ in boys aged (14-17) years prehypertension $6 \%$ had high blood pressure, however we have taken into consideration the chart with values specialised for children. Nawrot et al. (28) presented data on Belgian boys $(n=80)$ with a mean age of 17.4 years (range $15.8-19.6)$ in which $5 \%$ of the boys had resting systolic hypertension. In comparison to the research samples of the Hungarian children in our study, the amount with high blood pressure is about the six times than Belgium.

Research published by Aglony et al. (1) draws attention to the fact that the diagnosis of hypertension in children is complicated because 'normal' blood pressure values vary with age, sex and height. As a consequence, almost $75 \%$ of the cases of arterial hypertension and $90 \%$ of the cases of prehypertension in children and adolescents are currently undiagnosed. Blood pressure is a vital sign that is routinely obtained during a physical examination of adults, but only very seldom in children. Based on the reports of the European Society of Hypertension, Falkner et al. (9) emphasizes that adolescent prehypertension is much more frequent than researchers might have previously thought. For our study, we compared youth by age and also by RSBP. The number of subjects in each grouping differed and therefore some assumptions are that proportionally we have found the highest number of NRSBP subject in the G3 group and proportionally the highest number of HRSBP subject in the G2 group.

Differences were not significant regarding the age but we have found significant difference between groups based RSBP on body height, particularly $7.26 \mathrm{~cm}$ for NSBP vs. PRSBP and $8.99 \mathrm{~cm}$ between PSBP vs. HSBP. Based on these findings we can say that the age has no major influence on resting systolic blood pressure values, but if height reflects on growth associated with maturation, then it is possible that changes in stage of maturity can influence the resting systolic pressure. In this sample the body composition regarding the InBF\% does not influence the RSBP, therefore the effects of unfavorable body composition can be excluded. The BP values measured at maximum load show no difference regardless of the method of selection, except the maximal load pressure (MBP) by the RSBP grouping method, in which the HSBP group had significantly higher levels. This finding suggests that the load influenced the sympathoadrenal system response to increase the systolic blood pressure.

Regarding the DBP values, by the age group selected measurements have shown physiological values both at rest and at maximum load. In the group's differentiated based on RSBP, the DBP averages of the HRSBP group approaches critical values with significantly big relative deviation. DBP recorded at maximum load exceed $(60 \mathrm{mmHg})$ in every group, although relative deviation is at $50 \%$. We can say that regardless of the grouping method the differences in DBP values can be best described with a very high rate of individual variation. Differences in the averages of calculated PP and MAP based on age groups are "only" significant between G1 vs. G2 and G1 vs. G3, while groups selected based on RSBP show significant differences in all three groups. Results based on RVO2max show no difference 
regardless of selection, which means that we can find children with normal or high blood pressure with either good or bad performance. Differences in Q, O2P, VE, RVE selected by age groups validate the well-known physiological evidences, while the groups selected by blood pressure also contain children affected by high blood pressure.

In summary, we can say that the evidences mentioned the literature have been confirmed and this truly prevail in regards of body height, so the maturation process and their effect on formation of resting blood pressure in the samples that have been selected based on RSBP groups is present. There have been children who had high blood pressure even though their body composition was considered as normal and the measured aerobe capacity was excellent. There have been cases that showed completely opposing results. The difference between the averages of systolic and diastolic blood pressure measured at rest and at maximum load is only so much as we have measured between the resting pressure values. It is very likely that the reason behind these high pressure values is the vegetative over-regulation that comes into effect during the exercises. If this is true, then it is of outmost importance to mentally prepare the participant, and to adjust our expectations to actual fitness conditions. A possible answer to the condition of these children would be an individual training program consisting of exercises that are personalized and adjusted to their current fitness level (36).

The findings provide evidence that growth and maturation may have an impact on the development of systolic hypertension. A children who grows and develop into adolescence, appear to develop higher resting systolic pressures. It is possible that with maturation, development of left ventricle mass might provide a higher systolic blood pressure due to the ejection volumes of blood. This cross-sectional study does not provide conclusive evidence however. The development of heart function and its impact on blood pressure would require longitudinal data to validate statements. However, these results suggest the need for routine blood pressure measurements in children and adolescents as required by clinical guidelines, for more attention to co-existing other cardiovascular risk factors and for a sustained focus on healthy lifestyles that can be learned best at a young age (14).

\section{Funding sources}

This work was supported by the European Union and co-financed by the Europian Social Fund (TÁMOP 3.1.13), the Hungarian School Sport Federation and the Cooper Institute.

\section{REFERENCES}

1. Aglony M, Acevedo M, Ambrosio G: Hypertension in adolescents. Expert Rev. Cardiovasc. Ther. 7(12), 15951603 (2009)

2. American Academy of Pediatrics, Committee on Nutrition: Salt intake and eating patterns of infants and children in relation to blood pressure. Pediatrics 53, 115-121 (1974)

3. Bonanno JA, Lies JE: Effects of physical training on coronary risk factors. Am. J. Cardiol. 33, 760-764 (1974)

4. Boyer JL: Coronary heart disease as a pediatric problem: prevention through behavior modification. Am. J. Cardiol. 33, 784-786 (1974)

5. Boyer JL, Kasch FW: Exercise therapy in hypertensive men. JAMA, 211, 1668-1671 (1970)

6. Comstock GW: An epidemiologic study of blood pressure levels in a biracial community in the southern United States. Am. J. Epidemiol. 168(7), 733-777 (2008)

7. de Castro FJ, Biesbroeck R, Erikson C, Farrell P, Leong W, Murphy D, Green R: Hypertension in adolescents. Clin. Pediatr. 15, 24-26 (1976)

8. Epstein FH, Eckoff RD (1967): The epidemiology of high blood pressure - geographic distributions and etiological factors. In: The Epidemiology of Hypertension, eds. Stamler J, Stamler R, New York: Grune and Stratton, pp. 155-166. 
9. Falkner B, Lurbe E, Schaefer F: High blood pressure in children: clinical and health policy implications. J. Clin. Hypertens. (Greenwich). 12(4), 261-276 (2010)

10. Cs. Farsang (2013) Guidebook of Hypertension and Cardiovascular Prevention. Publisher: Medintel, Budapest. (In Hungarian: Farsang Cs (2013) A hypertóniaés a cardiovasculárisprevenciókézikönyve.) Medintel Könyvkiadó, Budapest.

11. Feinleib M, Garrison RJ, Fabsitz R, Christian JC, Hrubec Z, Borhani NO, Kannel WB, Rosenman R, Schwartz JT, Wagner JO: The NHLBI Twin Study of cardiovascular disease risk factors: methodology and summary of results. Am. J. Epidemiol. 106, 284-285 (1977)

12. Fixler DE, Laird WP, Fitzgerald V, Stead S, Adams R: Hypertension screening in schools: results of the Dallas study. Pediatrics, 63, 32-36 (1979)

13. Hahn L: The relation of blood pressure to weight, height and body surface area in schoolboys aged 11 to 15 years. Arch. Dis. Child. 27, 43-53 (1952)

14. Havlik RJ, Garrison RJ, Feinleib M, Kannel WB, Castelli WP, McNamara PM: Blood pressure aggregation in families. Am. J. Epidemiol. 110(3), 304-312 (1979)

15. Henry JP, Cassel JC: Psychosocial factors in essential hypertension. Recent epidemiologic and animal experimental evidence. Am. J. Epidemiol. 90(3), 171-200 (1969)

16. Heyden S, Bartel AG, Hames CG, McDonough JR: Elevated blood pressure levels in adolescents, Evans County, Georgia. Seven-year follow-up of 30 patients and 30 controls. JAMA, 209(11), 1683-1689 (1969)

17. Joubert K, Darvay S, Gyenis Gy, Éltető Ö, Mag K, van’t Hof M, Ágfalvi R: The results of the National Longitudinal Child Growth Study from birth to 18 years of age. Central Statistical Office (CTO) Demographic Research Institute, Budapest. 2006/2. (In Hungarian: Az Országos Longitudinális Gyermeknövekedés-vizsgálat eredményei születéstől 18 éves korig. KSH Népességtudományi Kutatóintézet, Budapest. 2006/2.)

18. Kilcoyne MM, Richter WR, Alsup AP: Adolescent hypertension: I. detection and prevalence. Circulation. 50, $758-764$ (1974)

19. Levine LS, Lewy JE, New MI: Hypertension in high school students. Evaluation in New York City. NY State J. Med. 76, 40-44 (1976)

20. Lieberman E: Essential hypertension in children and youth: a pediatric perspective. J. Pediatr. 85(1), 1-11 (1974)

21. Loggie JM, New MI, Robson AM: Hypertension in the pediatric patient: A reappraisal. J. Pediatr. 94, 685-689 (1979)

22. Loggie JM, Rauh LW: Persistent systemic hypertension in the adolescent. Med. Clin. North. Am. 59(6), 1371$1383(1975)$

23. Londe S, Goldring D, Gollub SW, Hernandez A (1977): Blood pressure and hypertension in children: studies, problems, and perspectives. In: Juvenile Hypertension, eds. New MI, Levine LS, New York, Raven Press, pp. $13-24$.

24. McDonough JR, Garrison GE, Hames CG: Blood pressure and hypertensive disease among negroes and whites: A study in Evans County, Georgia. Ann. Intern. Med. 61(2), 208-228 (1964)

25. McLain LG: Hypertension in childhood: A review. Am. Heart. J. 92(5), 634-647 (1976)

26. National High Blood Pressure Education Program Working Group on High Blood Pressure in Children and Adolescents: The fourth report on the diagnosis, evaluation, and treatment of high blood pressure in children and adolescents. Pediatrics, 114, 555 (2004)

27. Montoye HJ, Metzner HL, Keller JB, Johnson BC, Epstein FH: Habitual physical activity and blood pressure. Med. Sci. Sports, 4, 175-181 (1972)

28. Nawrot TS, Hoppenbrouwers K, Den Hond E, Fagard RH, Staessen JA: Prevalence of hypertension, hypercholesterolemia, smoking and overweight in older Belgian adolescents. Eur. J. Public Health, 14(4), 361365 (2004)

29. Neuhauser H, Thamm M: Blood pressure measurement in the German Health Interview and Examination Survey for Children and Adolescents (KiGGS). Methodology and initial results. Bundesgesundheitsblatt Gesundheitsforschung Gesundheitsschutz. 50(5-6), 728-735 (2007)

30. Rance CP, Arbus GS, Balfe JW, Kooh SW: Persistent systemic hypertension in infants and children. Pediatr. Clin. North. Am. 21(4), 801-824 (1974)

31. Scammon, RE (1930): The measurement of the body in childhood. In Harris, JA, Jackson, CM, Paterson, DG, Scamon, RE: The measurement of man. University of Minnesota Press, Minnesota, 173-215.

32. Sorof JM: Systolic hypertension in children: benign or beware? Pediatr. Nephrol. 16(6), 517-525 (2001) 
33. Stamler J (1980): Improved lifestyles: their potential for the primary prevention of atherosclerosis and hypertension in childhood. In: Childhood Prevention of Atherosclerosis and Hypertension, eds. Lauer RM, Shekelle RB, New York, Raven Press, pp. 30-36.

34. Stamler J, Stamler R, Pullman TN: The epidemiology of hypertension. New York: Grune \& Stratton, Inc., 1967.

35. Stamler J, Stamler R, Riedlinger WF, Algera G, Roberts RH: Hypertension screening of 1 million Americans. Community Hypertension Evaluation Clinic (CHEC) program, 1973 through 1975. JAMA, 235(21), 22992306 (1976)

36. Veterans Administration Cooperative Study on Antihypertensive Agents: Effects of treatment on morbidity in hypertension. Results in patients with diastolic blood pressures averaging 115 through $129 \mathrm{mmHg}$. JAMA, 202, 1028-1034 (1967)

37. Veterans Administration Cooperative Study on Antihypertensive Agents: Effects of treatment on morbidity in hypertension. II. Results in patients with diastolic blood pressure averaging 90 through $114 \mathrm{~mm}$ Hg. JAMA, 213, 1143-1152 (1970)

38. Voors AW, Webber LS, Berenson GS: Time course studies of blood pressure in children: The Bogalusa Heart Study. Am. J. Epidemiol. 109(3), 320-334 (1979)

39. Weiner JES, Lourie JA (Eds.) (1969): Human Biology. A Guide to Field Methods. IBP Handbook, No. 9. Blackwell Scientific Publishers, Oxford. 